\title{
A NEW RECORD AND A REDESCRIPTION OF TYPHLODROMIPS MONTANUS (WAINSTEIN, 1962) COMB.N. (ACARI: PHYTOSEIIDAE) FROM THE ALTAI REPUBLIC, RUSSIA
}

\author{
Vladimir A. Khaustov ${ }^{1}$, İsmail Döker ${ }^{1,2^{*}}$, Omid Joharchi ${ }^{1}$ and Alexander A. Khaustov \\ ${ }^{1} \mathrm{X}-\mathrm{BIO}$ Institute, Tyumen State University, Tyumen, Russia \\ ${ }^{2}$ Acarology Laboratory, Department of Plant Protection, Agricultural Faculty, Cukurova \\ University, Adana, Turkey \\ *corresponding author; e-mail: idoker@cu.edu.tr
}

\begin{abstract}
Typhlodromips montanus (Wainstein) comb.n. (Acari: Phytoseiidae) is reported for the first time from Russia. It is redescribed and illustrated based on female and male specimens collected from the Altai Republic, Russia. This species was previously placed in the genus Neoseiulus Hughes. However, it fits well with the current concept of the genus Typhlodromips De Leon, due to the combination of: the presence of macrosetae on Gell, Gelll and Tilll, and fixed digit of chelicera with more than six teeth.
\end{abstract}

KEY WORDS: Predatory mite, Amblyseiinae, taxonomy, first report, fauna.

DOI: 10.21684/0132-8077-2020-28-2-203-211

\section{INTRODUCTION}

Predatory mites of the family Phytoseiidae (Acari: Mesostigmata) are of great importance due to their potential as biological control agents of other mites that feed on plants, as well as of small soft-bodied insects such as thrips and whiteflies (McMurtry et al. 2013). Proper identification of phytoseiid mites is crucial in the implementation of biological control programs because morphologically close phytoseiid species may vary significantly in terms of their feeding habits (Gerson 2014). Systematic studies of this mite family date back to the early 1960s in Russia (Wainstein 1962a; Kolodochka 1978, 2006; Beglyarov 1981). Although many species from Russia have been described, most of the descriptions are poor and lack many morphological details necessary to distinguish different phytoseiid species. In this regard, redescriptions are important since they help avoid taxonomic confusion.

Typhlodromips montanus (Wainstein, 1962b) comb.n. was described from Kazakhstan. The original description is brief: it includes simple illustrations of dorsal and ventral idisoma, chelicera and leg IV, as well as a few setae measurements. In addition, Wainstein (1977) illustrated this species' spermatheca. The description of this species is incomplete: it lacks most of the important morphological details, including the dorsal setae lengths and leg chaetotaxy (Chant and McMurtry 2007; Papadoulis et al. 2009). Chant and McMurtry (2007) included this species in the genus Neoseiulus Hughes, probably due to the inadequacies mentioned above. However, our examination of the current specimens shows that this species does not fit the definition of Neoseiulus. On the contrary, it is identical to the genus Typhlodromips De Leon, as described by Chant and McMurtry (2005).

\section{MATERIALS AND METHODS}

Leaves of various plants were collected during our expedition to the Altai Republic, Russia, in July-August 2020. The mites were collected directly from plant leaves using the Discovery V8 stereomicroscope and placed in vials filled with $96 \%$ ethanol. Specimens were cleared in lactic acid solution and mounted in Hoyer's medium as suggested by Walter and Krantz (2009). The taxonomic system follows that of Chant and McMurtry (2007). Setal nomenclature for the dorsal idiosoma follows that of Lindquist and Evans (1965), as adapted by Rowell et al. (1978). Setal nomenclature for the ventral idiosoma follows that of Chant and Yoshida-Shaul (1991). The chaetotaxy of the palp tibia and tarsus, as well as of the distal part of tarsus I follows that of Jackson (1974), with minor modification by Khaustov (2020). Chaetotaxy of other parts of legs and palps follows that of Evans (1963a, 1963b, 1969). The nomenclature for the dorsal solenostomes and poroids follows that of Athias-Henriot (1975). The nomenclature for the ventral surface of idiosoma follows that of Johnston and Moraza (1991). The terminology of the morphological structures of spermatodactyl follows that of Beard (2001). Measurements are given in micrometers $(\mu \mathrm{m})$ and presented as a mean, followed by a range in parentheses. Morphological observations, illustrations and measurements were prepared using the Axio Imager A2 compound microscope (Carl Zeiss, Germany), equipped with 


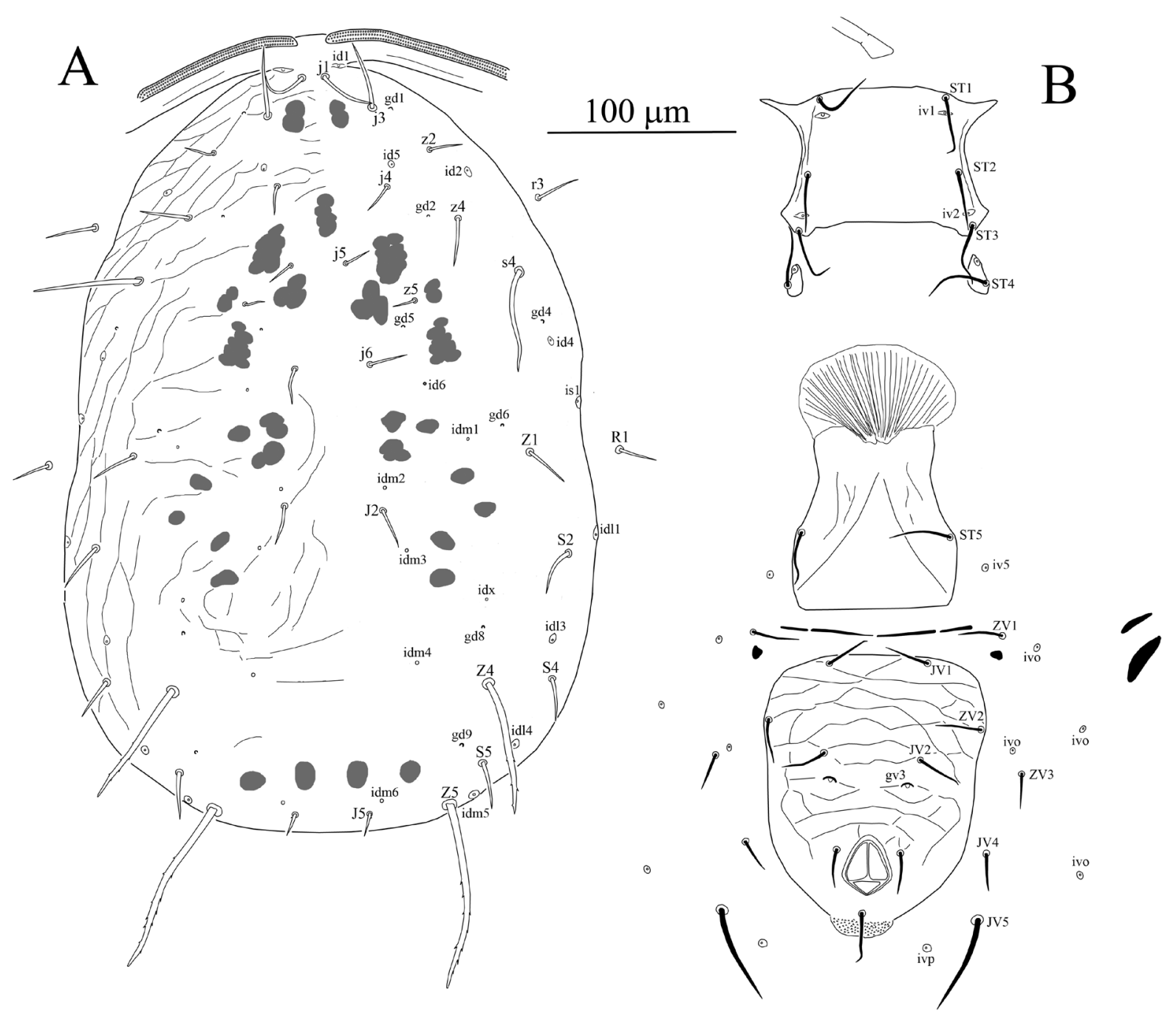

Fig. 1. Typhlodromips montanus (Wainstein, 1962) comb.n., female. A—dorsal idiosoma; B-ventral idiosoma.

the differential interference contrast (DIC) and the phase contrast optical systems. Micrographs were taken with the Olympus OM-D Em-10 digital camera. The dorsal shield length was measured along the midline, at level of $j 1$ setae and $J 5$ setae. All examined materials have been deposited in the mite collection of the Tyumen State University Museum of Zoology, Tyumen, Russia.

\section{SYSTEMATICS}

Family Phytoseiidae Berlese, 1916

Subfamily Amblyseiinae Muma, 1961

Tribe Typhlodromipsini Chant and McMurtry, 2005

Genus Typhlodromips De Leon, 1965

\section{Typhlodromips montanus (Wainstein) new combination}

(Figs. 1-6)
Amblyseius montanus Wainstein, 1962b: 234; Wainstein 1977: 239.

Amblyseius (Amblyseius) montanus Wainstein, in Ehara 1966: 22.

Neoseiulus montanus (Wainstein), in Kolodochka 2006: 233; Chant and McMurtry 2007: 29.

Female ( $\mathrm{n}=5$ ) (Figs. 1-6). Dorsum (Fig. 1A). Dorsal setal pattern 10A:9B ( $r 3$ and $R 1$ off shield). Dorsal shield, sclerotized, with some patches of reticulations with anterolateral and posterolateral scales, with waist at level of seta $R 1$. Bearing seven pairs of solenostomes $(g d 1, g d 2, g d 4, g d 5, g d 6, g d 8$ and $g d 9$ ). Sixteen pairs of poroids (sensilla) visible on the shield. Muscle-marks (sigilla) visible mostly on podosoma, length of dorsal shield 385 (380-390), width (distance at level of $s 4$ ) 233 (230-237), width (distance at level of S4) 257 (251-273). Dorsal setae smooth, except J5 (with one small barb), $Z 4$ and $Z 5$, which are serrated and 


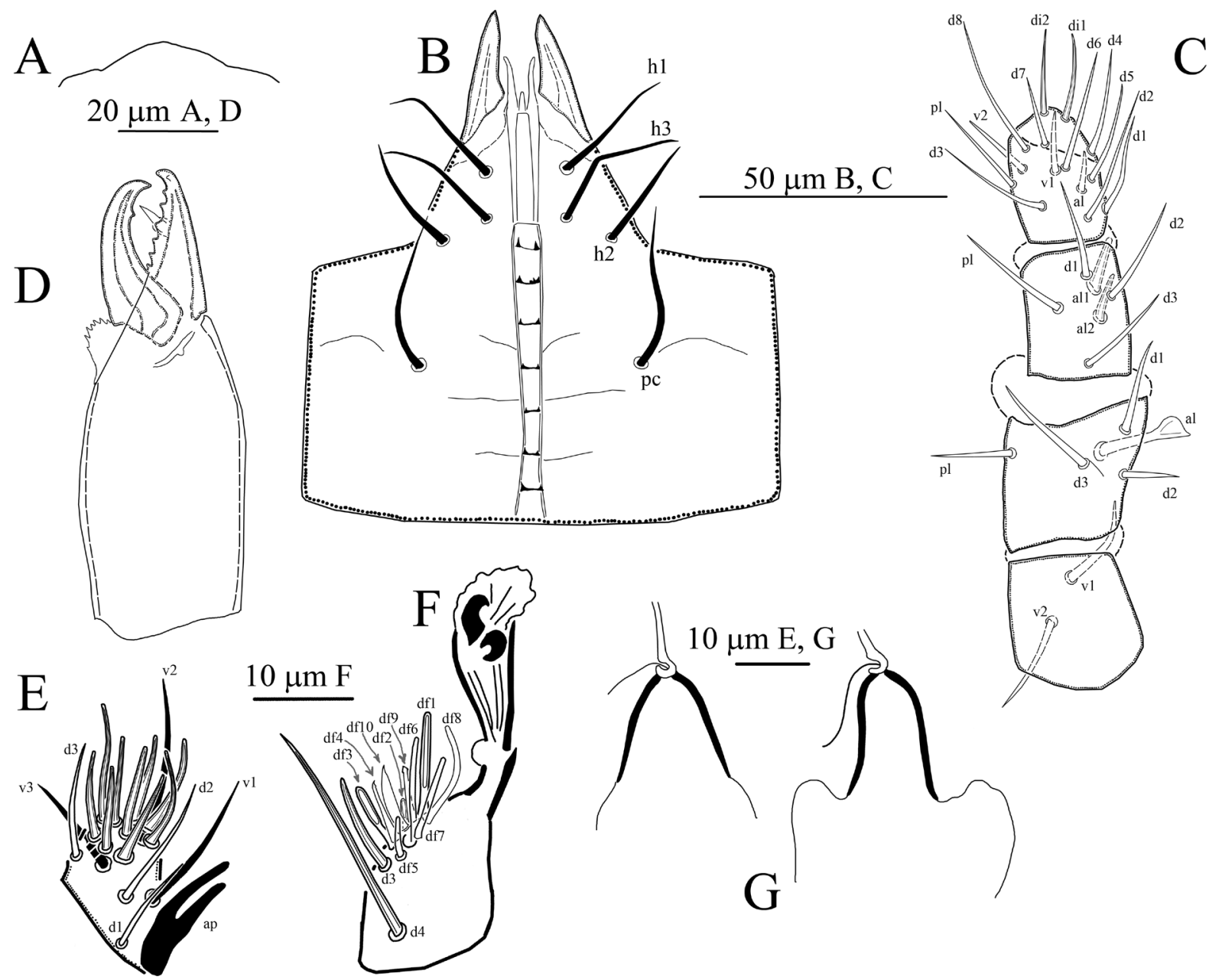

Fig. 2. Typhlodromips montanus (Wainstein, 1962) comb.n., female. A-anterior margin of epistom; B-subcapitulum; C - dorsal view of left palp excepting tarsus; D — chelicera; E — dorsal view of left palp tarsus; F - apical sensorial setal cluster area and setae $d 3, d 4$ of tarsus I, left leg, dorso-lateral view; G-spermatheca.

somewhat stout. Measurements of dorsal setae as follows: 1127 (25-28),j337(35-39), j4 15 (13-17), j5 13 (11-15), j6 19 (16-23), J2 20 (18-22), J5 11 (10-12), z2 19 (17-21), z4 23 (22-24), z5 11 (1012), Z1 22 (19-24), Z4 72 (67-77), Z5 99 (92-105), s4 55 (52-56), S2 24 (21-29), S4 22 (21-24), S5 23 (20-25), r3 21 (18-23) and R1 20 (18-21).

Peritreme. Long, and extending to level of setae $j 1$.

Venter (Fig. 1B). Ventral setal pattern 14: JV3:ZV. Sternal shield smooth, lightly sclerotized; with three pairs of setae (ST1, ST2 and ST3) and two pairs of pores (iv1 and iv2); length (ST1-ST3) 69 (67-71), width (distance between setae ST2) 77 (74-80); metasternal setae ST4 and pair of pores (iv3) situated on metasternal shields. Genital shield striated; narrower than ventrianal shield, width at level of genital setae (ST5) 79 (74-81), para-genital poroids iv5 on integument. Ventrianal shield pentagonal, reticulated. Three pairs of pre-anal setae
$(J V 1, J V 2$ and $Z V 2)$; and pair of crescentic solenostomes $(g \vee 3)$ posteromesad setae $J V 2$, distance between pre-anal pores 36 (31-45). Pair of para-anal $(P a)$ and post-anal setae $(P s t)$. Length of ventrianal shield 137 (136-140), width at level of setae $Z V 2$ 113 (108-126). Setae ZV1, ZV3, JV4, JV5 and five pairs of poroids on integument surrounding ventrianal shield. Setae JV5 smooth, much longer than other ventral setae, 55 (52-57) in length.

Gnathosoma (Figs 2A, 2B, 2C, 2E). Anterior margin of epistome rounded and smooth. Hypostomal groove with seven transverse rows of denticles, each row with two or three teeth; subcapitular setae h1 25 (24-25), h2 24 (23-24) h3 26 (25-26), slightly shorter than palp coxal setae (pc) 29 (2829). Chaetotaxy of palps: trochanter with two setae; femur with five setae; genu with six setae; tibia with 14 setae; tarsus with 15 setae.

Chelicera (Fig. 2D). Fixed digit 31 (30-32) long, with seven teeth, six of them prominent and 
A

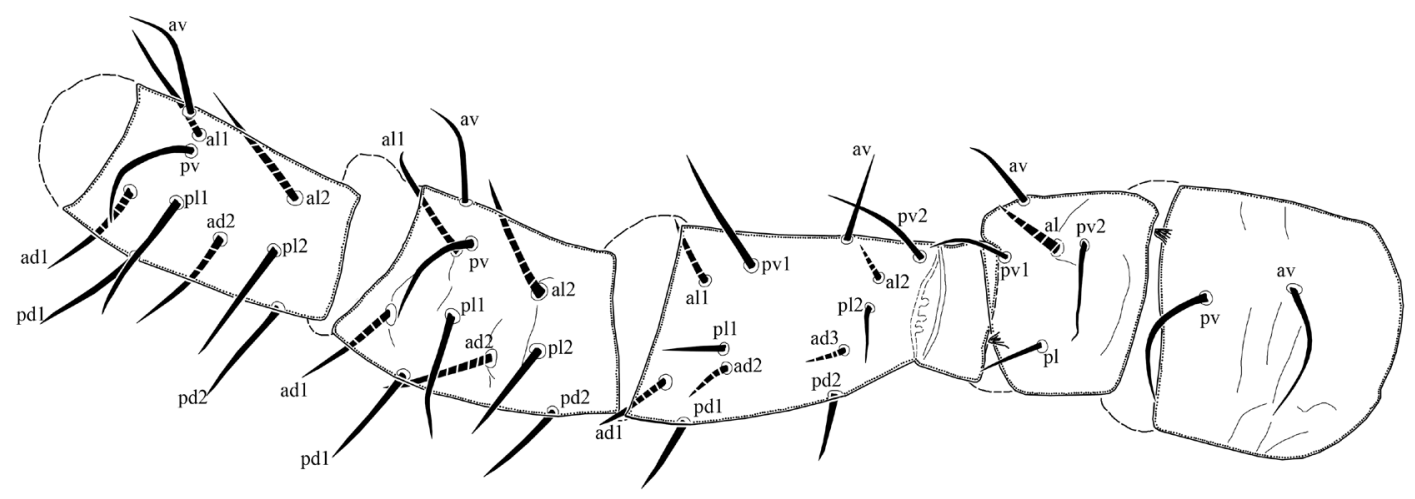

$50 \underline{\mu \mathrm{m} \mathrm{A}, \mathrm{B}, \mathrm{C}}$

\section{$50 \mu \mathrm{m} \mathrm{D}$}

B
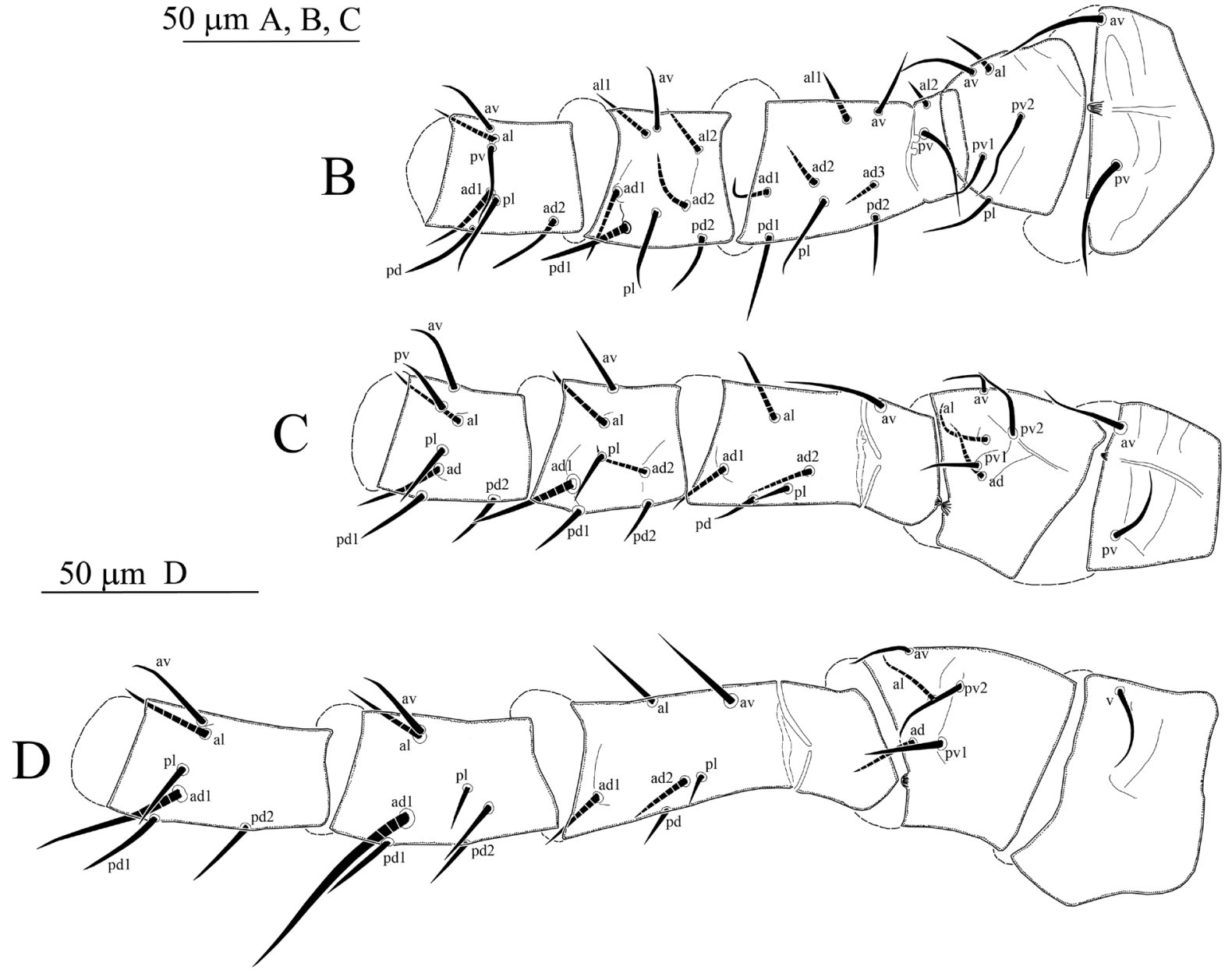

Fig. 3. Typhlodromips montanus (Wainstein, 1962) comb.n., female. A-D—left legs I-IV, respectively, except tarsi, ventral aspect.

one off-set tooth (gabelzhan), and pilus dentilis; movable digit 32 (31-33) long with one tooth.

Spermatheca (Fig. 2G). Atrium c-shaped, attached to calyx without neck. Calyx bell-shaped in most of examined specimens and slightly different (v-shaped) in some specimens, 16 (14-18) in length; major duct long; minor duct visible.

Legs (Figs 2F, 3, 4). Length of legs (base of coxae to base of claws): leg I 399 (396-404); leg II 319 (310-327); leg III 325 (318-331); leg IV
435 (428-442). Chaetotaxy as follows: Leg I: coxa 0 0/1 0/1 0, trochanter $10 / 10 / 21$, femur $23 / 12 / 2$ 2, genu 2 2/1 2/1 2, tibia $2 / 12 / 12$. Leg II: coxa $00 / 10 / 10$, trochanter $10 / 10 / 21$, femur $23 / 12 / 1$ 1, genu $22 / 12 / 01$, tibia $12 / 11 / 11$. Leg III: coxa $00 / 10 / 10$, trochanter $11 / 10 / 20$, femur $12 / 11 / 0$ 1, genu $12 / 12 / 01$, tibia $11 / 12 / 11$. Leg IV: coxa 0 0/1 $0 / 00$, trochanter $11 / 10 / 20$, femur $12 / 11 / 0$ 1, genu 1 2/0 2/1 1, tibia 1 1/0 2/1 1 . Chaetotaxy of tarsi II-IV typical for Phytoseiidae and bears 18 


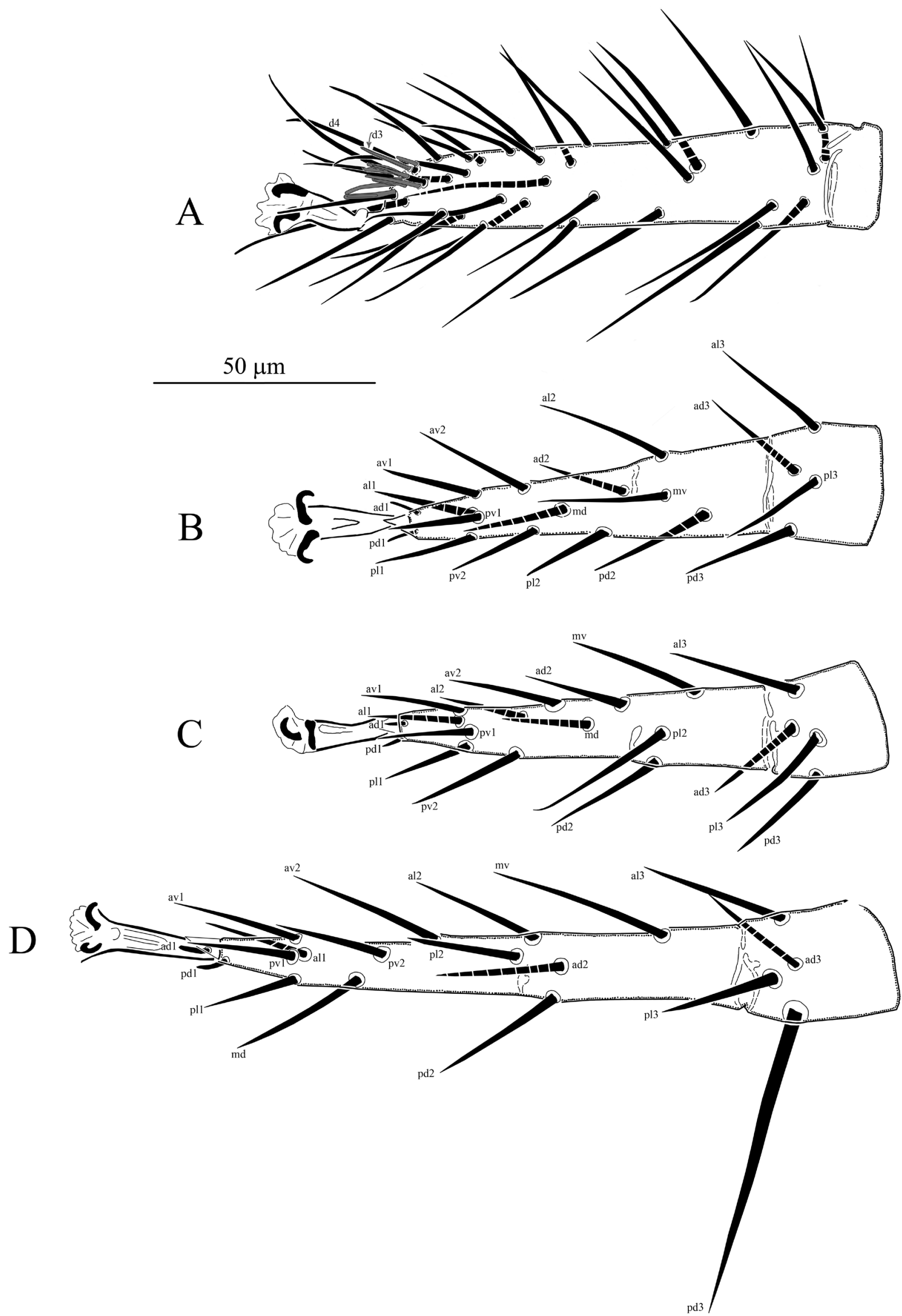

Fig. 4. Typhlodromips montanus (Wainstein, 1962) comb.n., female. Left tarsi I-IV respectively: A—dorsal aspect, B-D-ventral aspect. 


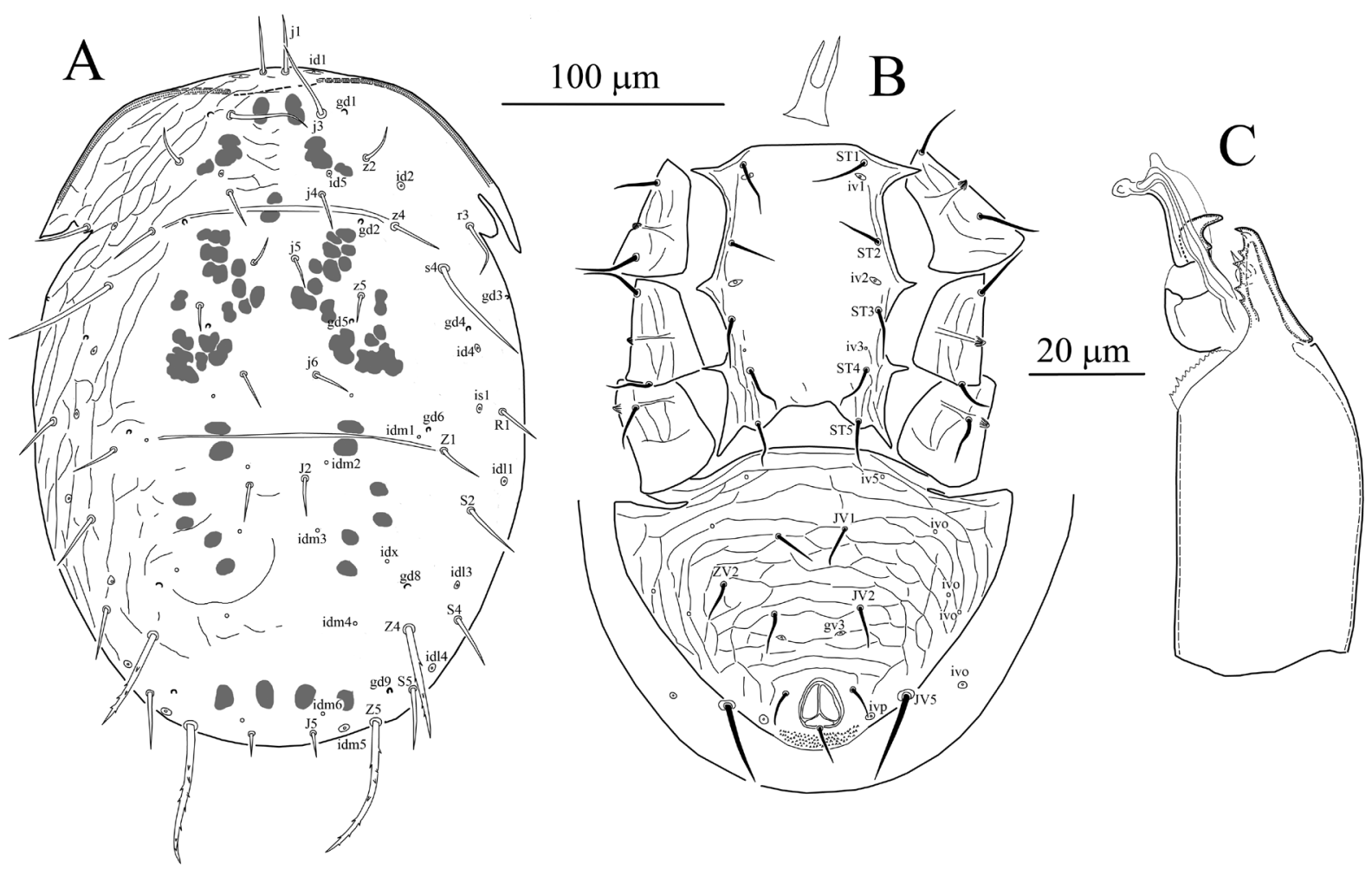

Fig. 5. Typhlodromips montanus (Wainstein, 1962) comb.n., male. A — dorsal idiosoma, B — ventral idiosoma, C—chelicera.

setae 3 3/2 3/2 $3+$ mv, md. Tarsus I with 36 setae, excluding apical sensorial setal cluster. Setae $d 3$ 10 with rounded tip, $d 427$ (26-28). Apical sensorial setal cluster includes 10 short setae of different shape (Fig. 2F). Measurements of macrosetae as follows: SgeII 25 (24-26), SgeIII 31 (30-33), StiIII 24 (23-25), SgeIV 56 (54-58), StiIV 40 (39-43), StIV 70 (68-72).

Male (n=3) (Fig. 5). Similar to female. Dorsum (Fig. 5A). Dorsal setal pattern 10A:9B (r3 and $R 1$ on shield), reticulated laterally. Bearing eight pairs of solenostomes $(g d 1, g d 2, g d 3, g d 4, g d 5$, $g d 6, g d 8$ and $g d 9$ ). Sixteen pairs of poroids (sensilla) visible on shield. Muscle-marks (sigilla) visible mostly on podosoma, length of dorsal shield 296 (280-312), width (distance at level of s4) 204 (191-220), width (distance at level of S2) 206 (191-220). Dorsal setae smooth except $Z 4$ and $Z 5$, which serrated and somewhat stout. Measurements of dorsal setae as follows: $j 124(23-24), j 3$ 37 (35-39), j4 15 (13-16), j5 12 (11-14), j6 18 (17-18), J2 17 (15-18) J5 11 (10-12), z2 19 (18-20), z4 24 (19-27), z5 10 (10-11), Z1 21 (21-22), Z4 51 (50-52), Z5 61 (57-65), s4 45 (43-48), S2 26 (25-28), S4 24 (23-26), S5 26 (25-27), r3 22 (21-24) and R1 18 (17-18).

Peritreme. Long, and almost extending to level between setae $j 1-j 3$.
Venter (Fig. 5B). Ventral setal pattern 14: JV$3: Z V$. Sternogenital shield striated posterolaterally, lightly sclerotized; with five pairs of setae (ST1, ST2, ST3, ST4 and ST5) and three pairs of pores (iv1, iv2 and iv3); length (ST1-ST5) 119 (117-122), width (distance between setae ST2) 66 (63-70). Ventrianal shield triangular; reticulated. Three pairs of pre-anal setae ( $J V 1, J V 2$ and $Z V 2$ ), seta $Z V 2$ absent in right side in illustrated specimen; and pair of crescentic solenostomes ( $g v 3)$ posteromesad setae $J V 2$, distance between pre-anal pores 31 (30-32). Pair of para-anal $(\mathrm{Pa})$ and post-anal setae (Pst). Length of ventrianal shield 137 (132-146), width at anterolateral corners 174 (161-186). Setae JV5 smooth, much longer than other ventral setae, 39 (37-43) in length.

Chelicera (Fig. 5C). Fixed digit 24 (23-25) long, with five teeth and pilus dentilis; movable digit 24 (23-24) long, with one tooth. Spermatophoral process wand-like, with slightly developed heel, toe digit-like.

Legs. Length of legs (base of coxae to base of claws): leg I 352 (345-362); leg II 269 (262-283); leg III 284 (275-290); leg IV 390 (385-396). Chaetotaxy same as in female. Measurements of macrosetae as follows: SgeII 19 (18-20), SgeIII 23 (22-24), StiIII 23 (22-23), SgeIV 41 (39-44), StiIV 34 (32-35), StIV 64 (62-67). 


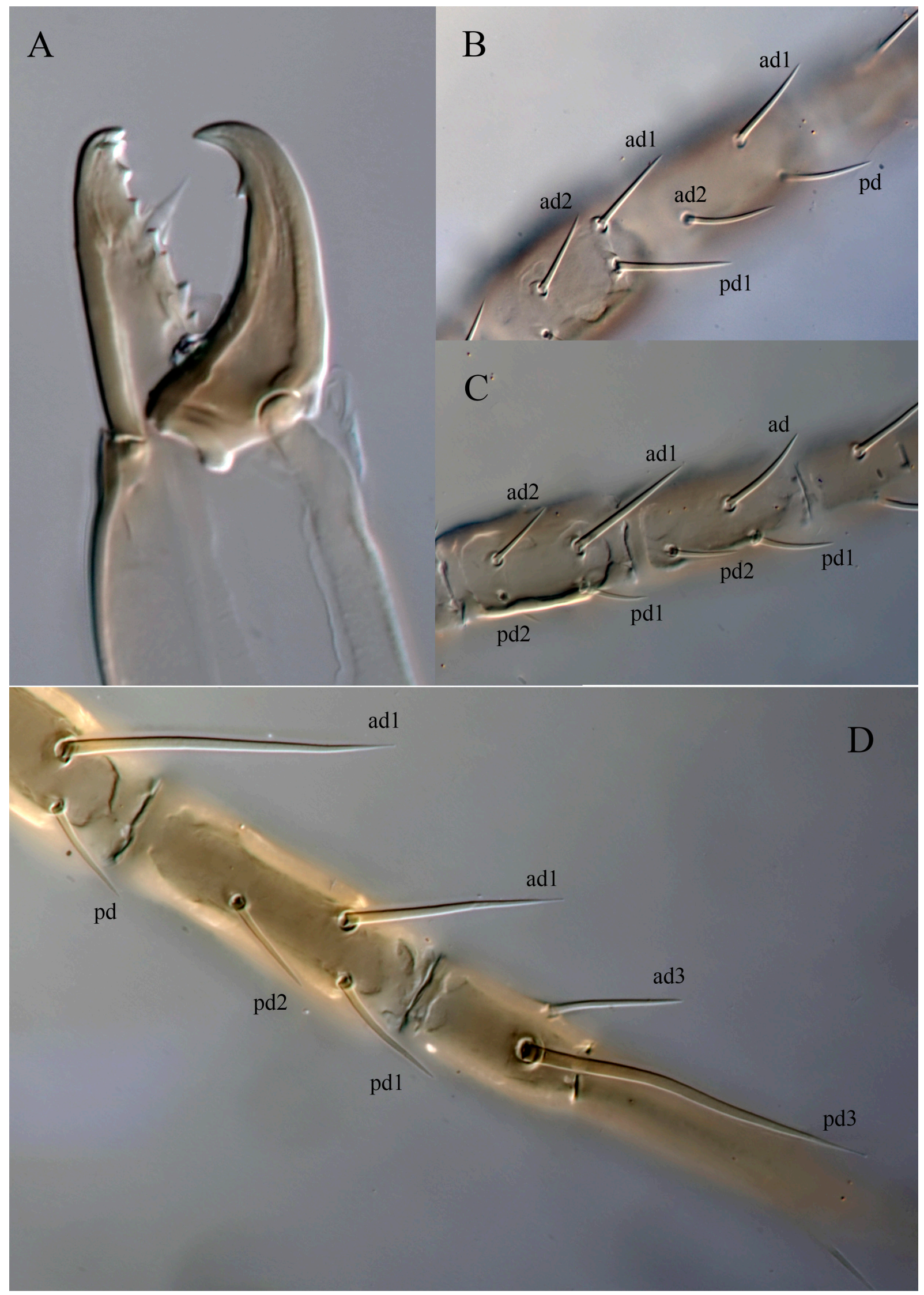

Fig. 6. DIC micrographs of Typhlodromips montanus (Wainstein, 1962) comb.n., female. A—chelicera, B-dorsal view of genu and tibia of right leg II, C - dorsal view of genu and tibia of right leg III, D — dorsal view of genu, tibia and basitarsus of right leg IV. 


\section{V.A. Khaustov et al.}

World distribution. Georgia, Kazakhstan, Ukraine (Demite et al. 2020, Kolodochka 2006), Russia (this study).

Material examined. 23 females and six males, Ulagan District, Altai Republic, Russia $\left(50^{\circ} 19^{\prime} \mathrm{N}\right.$, $87^{\circ} 44^{\prime} \mathrm{E}, 2,321 \mathrm{~m}$ a.s.1.), 31 July 2020, V.A. Khaustov coll., from various herbaceous plants.

Remarks. This is the first report of Typhlodromips montanus comb.n. from Russia. Morphological characters and measurements of the Russian specimens are very close to those in the original description. It was described based on 120 females collected from the grass and herbaceous plants from the mountains near the town of Alatau, Kazakhstan. However, the original description was poor: it featured only some basic illustrations and a few setae measurements (Wainstein, 1962b). This species was not included in any of the species groups in the most recent revision of the genus Neoseiulus Hughes by Chant and McMurtry (2003). Afterwards, Chant and McMurtry (2007) included this species in Neoseiulus, despite the fact that it has macrosetae on GeII, GeIII and TiIII, and seven teeth on the fixed digit of chelicera. In our opinion, this species fits well in the ariri species group of the genus Typhlodromips, due to the characters mentioned above and having a bell-shaped calyx of spermatheca (Chant and McMurtry 2005). In addition, its dorsal shield has some patches of reticulation with anterolateral and posterolateral scales, with a waist at the level of seta $R 1$. Most dorsal setae setiform, but setae $Z 4$ and $Z 5$ somewhat stout. Setae $z 2$ and $z 4$ are shorter than the distances between their bases; seta $z 4$ is shorter than the distance between its base and that of seta $s 4$; and the ratio seta $s 4: Z 1$ is about 2.5:1.0. In addition to leg IV, macrosetae are present on leg II and leg III. However, similar to some other species of the ariri species group, such as T. alpicola (Ehara, 1982) and T. septentrionalis (Karg, 1977), seta $s 4$ is also prominent and somewhat longer than the other anterolateral setae in T. montanus.

Furthermore, the geographic distribution of T. montanus is far outside of the most other species in the genus Typhlodromips and it has been collected only from Georgia, Kazakhstan, Ukraine (Kolodochka 2006) and Russia (this study). Interestingly, if we ignore the ratio setae $s 4: Z 1, T$. montanus fits well the definition of the genus Transeius by Chant and McMurtry (2004). In particular, it shows a close affinity to several species of Transeius: T. malovi (Beglyarov, 1981), T. tuvinensis (Beglyarov and Meshkov, 1988) and T. volgini (Wainstein and Beglyarov, 1971) based on the shape of the calyx of spermatheca and the shape of the ventrianal shield. It is interesting to note that all of the aforementioned species have the same geographic origin, and they all belong to the bellottii species subgroup. It seems that molecular analysis is necessary to draw a final conclusion about the generic placement of these species. Molecular analysis would also help clarify the importance of setae $s 4: Z 1$ ratio for tribe level systematics.

\section{ACKNOWLEDGEMENTS}

This study was supported by the grant from the Russian Science Foundation, project № 20-64-47015.

\section{REFERENCES}

Athias-Henriot, C. 1975. Nouvelles notes sur les Amblyseiini. II. Le relevé organotaxique de la face dorsale adulte (Gamasides, protoadéniques, Phytoseiidae). Acarologia, 17: 20-29.

Beard, J.J. 2001. A review of Australian Neoseiulus Hughes and Typhlodromips De Leon (Acari: Phytoseiidae: Amblyseiinae). Invertebrate Taxonomy, 15: 73-158.

Beglyarov, G.A. 1981. Opredelitel khishchnykh kleshey fitoseyid (Parasitiformes, Phytoseiidae) fauny SSSR. Ch. 1. [Keys to the determination of phytoseiid mites of the USSR]. In: Information Bulletin International Organization for Biological Control of Noxious Animals and Plants, East Palaearctic Section. No. 2. Leningrad. 97 pp. [In Russian]

Beglyarov, G.A. and Meshkov, Yu.I. 1988. [A new species of the genus Amblyseius (Parasitiformes, Phytoseiidae) from Tuva]. Zoologicheskii Zhurnal, 7: 1079-1080 [In Russian].

Chant, D. A. and McMurtry, J. A. 2004. A review of the subfamily Amblyseiinae Muma (Acari: Phytoseiidae): Part III. The tribe Amblyseiini Wainstein, subtribe Amblyseiina n. subtribe. International Journal of Acarology, 30: 171-228.

Chant, D. A. and McMurtry, J.A. 2005. A review of the subfamily Amblyseiinae Muma (Acari: Phytoseiidae) Part VII. Typhlodromipsini n. tribe. International Journal of Acarology, 31: 315-340.

Chant, D.A. and McMurtry, J.A. 2007. Illustrated Keys and Diagnoses for the Genera and Subgenera of the Phytoseiidae of the World (Acari: Mesostigmata). Indira Publishing House, West Bloomfield. 219 pp.

Chant, D.A. and Yoshida-Shaul, E. 1991. Adult ventral setal patterns in the family Phytoseiidae (Acari: Gamasina). International Journal of Acarology, 17: 187-199.

Demite P.R., Moraes G.J. de, McMurtry J.A., Denmark H.A. and Castilho R.C. 2020. Phytoseiidae Database. www.lea.esalq.usp.br/phytoseiidae 
Ehara, S. 1966. A tentative catalogue of predatory mites of Phytoseiidae known from Asia, with descriptions of five new species from Japan. Mushi, 39: 9-30.

Ehara, S. 1982. Two new species of phytoseiid mites from Japan (Acarina: Phytoseiidae). Applied Entomology and Zoology, 17: 40-45.

Evans, G. O. 1963a. Observations on the chaetotaxy of the legs in the free-living Gamasina (Acari: Mesostigrnata). Bulletin of the British Museum (Natural History) Zoology, 10: 275-303.

Evans, G.O. 1963b. Some observations on the chaetotaxy of the pedipalps in the Mesostigmata (Acari). Annals and Magazine of Natural History, 13: 513-527.

Evans, G. O. 1969. Observations on the ontogenetic development of the chaetotaxy of the tarsi of legs II-IV in the Mesostigmata (Acari). In: G. O. Evans (Ed.). Proceedings of the $2^{\text {nd }}$ International Congress of Acarology (Budapest). Budapest, pp. 195-200.

Gerson, U. 2014. Pest control by mites (Acari): present and future. Acarologia, 54: 371-394.

Jackson, G.J. 1974. Chaetotaxy and setal morphology of the palps and first tarsi of Phytoseiulus persimilis A.-H. (Acarina: Phytoseiidae). Acarologia, 16: 583-594.

Johnston, D.E. and Moraza, M.L. 1991. The idiosomal adenotaxy and poroidotaxy of Zerconidae (Mesostigmata: Zerconina). In: F. Dusbábek and V. Bukva (Eds.). Modern Acarology. Academia, Prague, vol. 2, pp. 349-356.

Karg, W. 1977. Zur Kenntnis der Gattung Amblyseius Berlese, 1904. Abhandlungen und Berichte des Naturkundemuseums Gorlitz, 51: 1-9.

Khaustov, V.A. 2020. Review of Amblyseius Berlese (Acari: Phytoseiidae) in Western Siberia, Russia. Acarologia, 60: 769-805.

Kolodochka, L.A. 1978. [Manual for the Identification of Plant-inhabiting Phytoseiid Mites]. Akademii Nauk Ukrainian SSR, Instituta Zoologii, Naukova Dumka, Kiev. 79 pp. [In Russian].

Kolodochka, L.A. 2006. [Phytoseiid mites of the Palaearctic Region (Parasitiformes, Phytoseiidae): faunistic, taxonomy, ecomorphology, evolution]. Vestnik Zoologii, suppl. 21: 1-250. [In Russian].

Lindquist, E.E. and Evans, G.O. 1965. Taxonomic concepts in the Ascidae with a modified setal nomenclature for the idiosoma of the Gamasina (Acarina: Mesostigmata). Memoirs of the Entomological Society of Canada, 47: 1-64.

McMurtry J.A., Moraes G. J. de, Sourassou N.F. 2013. Revision of the lifestyles of phytoseiid mites (Acari: Phytoseiidae) and implications for biological control strategies. Systematic and Applied Acarology 18: 297.

Papadoulis, G.Th., Emmanouel, N.G. and Kapaxidi, E. V. 2009. Phytoseiidae of Greece and Cyprus (Acari: Mesostigmata). West Bloomfield, Indira Publishing House. 200 pp.

Rowell, H.J., Chant, D.A. and Hansell, R.I.C. 1978. The determination of setal homologies and setal patterns on the dorsal shield in the family Phytoseiidae (Acarina: Mesostigmata). The Canadian Entomologist, 110: 859-876.

Wainstein, B.A. 1962a. Revision du genre Typhlodromus Scheuten, 1857 et systematique de la famille des Phytoseiidae (Berlese 1916) (Acarina: Parasitiformes). Acarologia, 4: 5-30.

Wainstein, B. A. 1962b. [Some new predatory mites of the family Phytoseiidae (Parasitiformes) of the USSR fauna]. Entomologicheskoe Obozrenie, 41: 230-240. [In Russian]

Wainstein, B.A. 1977. [Family Phytoseiidae Berlese, 1916]. In: B. M. Ghilarov (Ed.). Identification Key to Mites Inhabiting Soil (Mesostigmata). Nauka, Leningrad, pp. 226-244. [In Russian]

Wainstein, B.A. and Beglyarov, G.A. 1971. [New species of the genus Amblyseius (Parasitiformes: Phtyoseiidae) from the Primorsky Territory]. Zoologicheskii Zhurnal, 50: 1803-1812. [In Russian].

Walter, D.E. and Krantz, G. W. 2009. Collecting, rearing and preparing specimens. In: G. W. Krantz and D.E. Walter (Eds.). A Manual of Acarology. $3^{\text {rd }}$ edition. Texas Tech University Press, Lubbock, Texas, pp. 83-95. 